Das Wasser ist klar, merklich gelblich gefärbt, gerachlos, von salzigem, styptischem, hintennach bitterem Geschmack. Gegen das Gefühl reagirt es nicht. Das Wasser entspringt dem Lias und unterem Oolith; die Liasbinke enthalten Gyps und Dolomit, aus deren Wechselwirkung das Bittersalz entstanden sein mag. (Ann. de Chim. et de Phys. 3. Sér. Tom. LX. pag. 479-497. December 1860.)

Dr. H. Ludwig.

\title{
Analyse der Schwefelquelle der Ponts de Martel (Canton Neuchatel).
}

Die Quelle entspringt mitten in einem Sumpfe, eine viertel Stunde von dem Dorfe gleichen Namens. In der Umgebung derselben bemerkt man einen Geruch nach HS. Das Wasser ist klar, farblos, besitzt keinen merklichen Wohlgeschinack; seine Temperatur ist $9^{0} \mathrm{C}$. 1 Liter:

Nach Professor Ch. Kopp enthält das Wasser in

$$
\begin{aligned}
& \mathrm{CaO}, \mathrm{SO}^{3}=0,0911 \text { Grm. } \\
& \mathrm{CaS}=0,0098 \\
& \mathrm{CaCl}=0,0050 \text { " } \\
& 2 \mathrm{CaO}, \mathrm{PO}^{5}=0,0044 \text { n } \\
& \mathrm{CaO}, \mathrm{S}^{2} \mathrm{O}^{2}=0,0014 \text { n } \\
& \mathrm{CaO}, 2 \mathrm{CO}^{2}=0,2150 \text { n } \\
& \mathrm{MgO}_{2} 2 \mathrm{CO}^{2}=0,1263 \quad \pi \\
& \mathrm{FeO}, 2 \mathrm{CO}^{2}=0,0040 \text { " } \\
& \mathrm{Al}^{2} \mathrm{O}^{3}=0,0010 \\
& \mathrm{Si} \mathrm{O}^{3}=0,0324 \text { " } \\
& \text { Organische Substanz }=\frac{0,0096 \quad \pi}{0,5000 \mathrm{Grm} .}
\end{aligned}
$$

frei an HS $=0,0060$, entsprechend 4 C.C. (L'Echo médicale. Mars 1860.)

Kromayer.

\section{Analyse der Eisenquelle von Brévine (Canton Neuchatel).}

F. Pagen stecher von Bern analysirte das Wasser. Er beschreibt es als ein klares, durchsichtiges Wasser (an der Quelle), welches sich aber, einige Zeit in der Flasche aufbewahrt, trübt, flockiges Ansehen bekommt, nach und nach sich wieder klärt, während ein gelbrother voluminöser Niederschlag sich bildet.

Beim Erwärmen des Wassers auf $30-40^{\circ} \mathrm{R}$. entwickelt es eine beträchtliche Menge von $\mathrm{CO}^{2}$ und $\mathrm{N}$, welchen letzteren 10 Proc. $\mathrm{O}$ beigemengt sind.

In 12 Unzen des Wassers sind enthalten:

$$
\begin{aligned}
\mathrm{CO}^{2} & =1,85 \text { Cub.-Zoll (Pariser) } \\
\mathrm{N} & =0,75, "
\end{aligned}
$$

